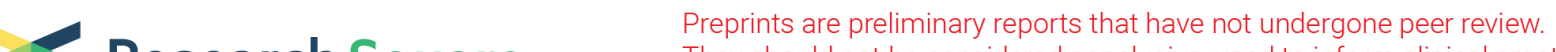 Research Square
They should not be onsidideded conllusive, used to inform clinical practice,
or referenced by the media salidated information.
}

\section{Prevalence of Hepatitis C Virus in Nigeria: a Protocol for Systematic Review and Meta-analysis}

Helen Chioma Okoye

University of Nigeria Teaching

Emmanuel Okechukwu Nna ( $\nabla$ e.nna@themping.org )

Biosystem Laboratories https://orcid.org/0000-0001-6791-2336

\section{Samuel Onuka}

Federal Medical Centre Umuahia

\section{Bamgboye M Afolabi}

Health Environment and Development Foundation

\section{Daniel Onwusulu}

Nnamdi Azikiwe University Teaching Hospital

\section{Amaka Obiageli Nnamani}

UNTH: University of Nigeria Teaching Hospital

\section{Richard Chinaza Ikeagwulonu}

Alex Ekwueme Federal University Teaching Hospital Abakaliki

\section{Augustine Nwakuche Duru}

UNTH: University of Nigeria Teaching Hospital

Dorathy Chinwe Obu

Alex Ekwueme Federal Teaching Hospital

Oluyemi Oluwatosin Akanni

Federal Neuro Psychiatric Hospital

\section{Chinonyelum Thecia Ezeonu}

Alex Ekwueme Federal University Teaching Hospital Abakaliki

Dorothy Omono Esangbedo

Providence Hospital

\section{Garba Yunusa}

Usmanu Danfodiyo University College of Health Sciences

\section{Motunrayo Coker}

University of Ibadan

\section{Uzoma Vivian Asiegbu}

Alex Ekwueme Federal University Teaching Hospital Abakaliki

Ngozika Okoye

INASP Nigeria

Uchenna Okeke 
Nigerian Navy

\section{Protocol}

Keywords: Hepatitis C virus, infection, Prevalence, blood donors, multiply transfused, people living with HIV/AIDS, pregnancy, children prisoners, test method, Nigeria

Posted Date: January 15th, 2021

DOl: https://doi.org/10.21203/rs.3.rs-144655/v1

License: (9) This work is licensed under a Creative Commons Attribution 4.0 International License. Read Full License 


\section{Abstract}

Background: Hepatitis $\mathrm{C}$ virus infection is a major cause of liver cirrhosis and is responsible for a quarter of all cases of liver cancers. Globally, about 71 million people are estimated to have chronic hepatitis C, with nearly 399,000 people dying from this infection, essentially due to liver cirrhosis and liver cancer. However, the exact pooled prevalence of hepatitis $C$ virus infection in Nigeria is unknown, hence the burden of the disease has not been adequately estimated.

Methods: A search strategy is developed using MeSH, text words, and entry terms. Nine databases will be searched, including PubMed, African Journals Online (AJOL), Embase, Google Scholar, Scopus, Cochrane Library, CINAHL, Web of Science, and ResearchGate. Eligible studies will be a) observational studies; b) published or retrievable in the English language; c) must have been conducted in Nigeria, and d) must report the main measurable outcome which is the prevalence of hepatitis $\mathrm{C}$ virus infection in Nigeria. Searches from databases will be exported into Distiller SR software for screening, selection and extraction of data items based on inclusion and exclusion criteria. Both quality scores and the risk of bias for individual studies will be assessed and reported in Distiller SR. Extracted data items will exported into the Comprehensive Meta-Analysis Software version 3 for for statistical analysis and forest plots. Studies will be assessed for methodological, clinical, and statistical heterogeneity. Funnel Plots will be used for assessing publication bias. Subgroup analysis will be performed using categorical data. The systematic review and meta-analysis will be reported according to the PRISMA 2015 Statement.

Discussion: Ethical approval will not be required since this study will be based on published data. This review will provide important data on the prevalence of hepatitis $C$ virus infection in Nigeria and the burden of the disease. The final report of this study will be published in a peer-reviewed journal and the findings will be made available to various policymakers and health experts that manage patients at risk or infected with the hepatitis $C$ virus.

Trial Registration Number: This protocol has been registered in PROSPERO; registration number: CRD42020213806

\section{Background}

Hepatitis $C$ virus is a single-stranded positive-sense virus that belongs to the Flaviviridae family(1). The virus naturally targets the hepatocytes and it is an important cause of viral hepatitis (2). Viral hepatitis resulting from the hepatitis $C$ virus is typically characterized by the development of irreversible chronic liver damage(3).

People of all age groups, gender, and in all locations can be affected by hepatitis C virus infection(4). Several researchers have reported varying prevalence rates of the infection in different populations and from one location to the other which may arise due to higher rates of exposure to a particular cohort as seen among people who are multiply transfused for a health condition(5). It could also be a reflection of unhealthy practices or on the other hand, the impact of improved health care delivery in different 
locations (6-8). The prevalence is also thought to vary depending on differences in study conduct as well as the method of detection, be it a rapid diagnostic test (RDT) or enzyme immunoassay (EIA) or polymerase chain reaction (PCR) $(2,6,9,10)$. It ranges from $0.1-17.5 \%$ in Africa(11). The prevalence in Nigeria has been reported in different study cohorts $(4,12,13)$.

Viral transmission is usually through the parenteral route commonly via transfusion of unscreened blood $(7,14)$. Other ways of transmission include mother-to-child transmission, sexual intercourse especially in those with risky sexual habits, needle stick injury among health workers, use of unsterile medical equipment, and intravenous drug abusers $(2,9,11,15,16)$.

Hepatitis $\mathrm{C}$ causes both acute and chronic infections. The clinical manifestation may vary and $80 \%$ of infected individuals may remain asymptomatic $(17,18)$. The symptomatic ones may present clinically with fever, nausea and vomiting, jaundice, abdominal and joint pain, and about $80 \%$ of them will progress to chronic disease $(19,20)$. Of these, $20-25 \%$ develop liver cirrhosis and cancer(17). Hepatitis $C$ virus infection typically runs an indolent course with a long period between the actual infection and manifestation of liver disease posing a challenge in linking the chronic hepatic complications to the infection(21).

Often, management of acute infections entails "watchful waiting", chronic infections are treated using pan-genotypic direct-acting antiviral (DAA) as recently recommended(17). Pan-genotypic DAA is difficult to access in certain countries due to its high cost as the majority of affected individuals are of the middleLow socio-economic class(3).

In Nigeria, the prevalence and burden of hepatitis $C$ virus infection are still unknown. This study aims to fill in the knowledge gap as this will stir up conversations with policymakers on plans for prevention and treatment of the infection on the national level. Currently, the hepatitis $C$ virus has no preventable vaccine even though it is treatable.

\section{Objective}

The main objective of this study is to determine the pooled prevalence of hepatitis $\mathrm{C}$ virus infection in Nigeria and to determine prevalences in subgroups including prisoners, blood donors, pregnant women, people living with HIV/AIDs (PLWHA), and sickle cell patients who are multiply transfused.

\section{Study objectives:}

1. To determine the pooled or overall prevalence of hepatitis $C$ virus infection in Nigeria.

2. To determine prevalence in subgroups such as children, adults, persons living with HIV/AIDS (PLWHA), people in prisons, blood donors, sex workers, sickle cell patients, pregnant women, and coinfection with HBV infection in Nigeria.

\section{Review Questions:}


1. What is the pooled prevalence of hepatitis $C$ virus infection in Nigeria?

2. What is the pooled hepatitis $C$ virus infection in sub-populations of children, adults, PLWHA, people in prisons, blood donors, sex workers, sickle cell patients, pregnant women, and co-infection with Hepatitis B virus in Nigeria?

3. What is the pooled prevalence based on detection methods?

\section{Methods}

\section{Study Design}

This is a protocol to enable a transparent, reproducible and reliable systematic review and meta-analysis on the prevalence of hepatitis $\mathrm{C}$ infections in Nigeria. It focuses on observational studies that report different test methods including rapid diagnostic tests, enzyme immunoassays, and PCR methods for detection of hepatitis $\mathrm{C}$ infections. There is no restriction on time frame for including studies.

\section{Study characteristics:}

Inclusion criteria are

a. observational studies such as cross-sectional studies, case-control studies, cohort studies, and historical cohort studies

b. studies must report the prevalence of hepatitis $C$ virus infection in Nigeria

c. studies that are published or retrievable in the English language and are available in electronic databases.

Exclusion criteria will be

a. narrative reviews, experimental and interventional studies;

b. letters to editors, reviews, commentaries, and editorials;

C. and duplicates of the same studies.

This review will be reported in line with Preferred Reporting Items for Systematic Reviews and MetaAnalyses (PRISMA 2015 Statement).

PICOS: In this study, participants are residents in Nigeria who are infected with hepatitis $\mathrm{C}$ virus. There is neither intervention nor a comparable group. The measurable outcome is the pooled prevalence of hepatitis $C$ virus infection in Nigeria. Subgroups are children, adults, persons living with HIV/AIDS, people in prisons, blood donors, sex workers, sickle cell patients, pregnant women, and co-infection with HBV in Nigeria and multiply transfused people. The subgroups are categorical. Moderators will include the type of testing methods: rapid diagnostic test, enzyme immunoassay, and PCR methods.

\section{Information sources}


The search will employ sensitive topic-based strategies designed for each database. Nine databases will be searched: PubMed, CINAHL, Embase, Web of Science, Google Scholar, AJOL, Cochrane library, ResearchGate, and Scopus will be included. Only observational studies retrievable in the English language will be included.

\section{Search strategy}

The search strategy will include MeSH terms, text words, and entry terms. The search strategies to be used in various databases are shown in Table 1.

Table 1

Search Strategy

\begin{tabular}{|c|c|c|}
\hline S/No & Database & Search strategy \\
\hline 1 & PubMed & $\begin{array}{l}\text { (((Hepaciviruses OR Hepatitis C-Like Viruses OR Hepatitis C Like Viruses OR } \\
\text { Hepatitis C-Like Virus OR Hepatitis C virus*) OR "Hepacivirus"[Mesh]) AND } \\
\text { ((Federal Republic of Nigeria OR Nigeria) OR "Nigeria"[Mesh]) }\end{array}$ \\
\hline 2 & AJOL & $\begin{array}{l}\text { (Hepaciviruses OR Hepatitis C-Like Viruses OR Hepatitis C Like Viruses OR } \\
\text { Hepatitis C-Like Virus OR Hepatitis C virus*) OR "Hepacivirus") AND ((Federal } \\
\text { Republic of Nigeria OR Nigeria) OR "Nigeria") }\end{array}$ \\
\hline 3 & $\begin{array}{l}\text { Google } \\
\text { Scholar }\end{array}$ & $\begin{array}{l}\text { (((Hepaciviruses OR Hepatitis C-Like Viruses OR Hepatitis C Like Viruses OR } \\
\text { Hepatitis C-Like Virus OR Hepatitis C Virus*) OR "Hepacivirus") AND ((Federal } \\
\text { Republic of Nigeria OR Nigeria) OR "Nigeria") }\end{array}$ \\
\hline 4 & $\begin{array}{l}\text { Cochrane } \\
\text { library }\end{array}$ & $\begin{array}{l}\text { Hepaciviruses OR Hepatitis C-Like Viruses OR Hepatitis C Like Viruses OR } \\
\text { Hepatitis C-Like Virus OR Hepatitis C virus* OR "Hepacivirus" AND Federal } \\
\text { Republic of Nigeria OR Nigeria OR "Nigeria" }\end{array}$ \\
\hline 5 & Embase & $\begin{array}{l}\text { (Hepaciviruses OR Hepatitis C-Like Viruses OR Hepatitis C Like Viruses OR } \\
\text { Hepatitis C virus* OR Hepacivirus [Mesh]) AND (Federal Republic of Nigeria OR } \\
\text { Nigeria [Mesh]) }\end{array}$ \\
\hline 6 & CINAHL & $\begin{array}{l}\text { (((Hepaciviruses OR Hepatitis C-Like Viruses OR Hepatitis C Like Viruses OR } \\
\text { Hepatitis C-Like Virus OR Hepatitis C virus*) OR "Hepacivirus"[Mesh]) AND } \\
\text { ((Federal Republic of Nigeria OR Nigeria) OR "Nigeria"[Mesh]) }\end{array}$ \\
\hline 7 & $\begin{array}{l}\text { Web of } \\
\text { Science }\end{array}$ & $\begin{array}{l}\text { Hepaciviruses OR Hepatitis C-Like Viruses OR Hepatitis C Like Viruses OR } \\
\text { Hepatitis C virus* OR Hepacivirus [Mesh]) AND (Federal Republic of Nigeria OR } \\
\text { Nigeria [Mesh]) }\end{array}$ \\
\hline 8 & $\begin{array}{l}\text { Research } \\
\text { Gate }\end{array}$ & $\begin{array}{l}\text { (((Hepaciviruses OR Hepatitis C-Like Viruses OR Hepatitis C Like Viruses OR } \\
\text { Hepatitis C-Like Virus OR Hepatitis C virus*) OR "Hepacivirus"[Mesh]) AND } \\
\text { ((Federal Republic of Nigeria OR Nigeria) OR "Nigeria"[Mesh]) }\end{array}$ \\
\hline 9. & Scopus & $\begin{array}{l}\text { (Hepaciviruses OR Hepatitis C-Like Viruses OR Hepatitis C Like Viruses OR } \\
\text { Hepatitis C virus* OR Hepacivirus [Mesh]) AND (Federal Republic of Nigeria OR } \\
\text { Nigeria [Mesh]) }\end{array}$ \\
\hline
\end{tabular}

\section{Data Extraction and Management}




\section{a. Data Extraction:}

Studies will be searched using the search strategy in Table 1. Studies will be screened and selected in the DistillerSR using the following levels:

a. level 1 is based on study design: only observational studies will be included; other study designs will be excluded.

b. level 2: studies will be screened by titles and abstracts using entry terms, keywords, and meSh terms.

c. level 3: studies will be screened by full-text reading using the same strategy.

d. level 4: snowballing of literature from included studies.

e. level 5: screening of outcomes: both primary and secondary outcomes will be identified at this level.

Seventeen reviewers are involved in this study. A pair of reviewers will independently screen studies in the DistillerSR. Conflicts will be resolved by a third independent reviewer. The review will be blinded.

\section{b. Selection process:}

Screened studies will be selected based on pre-defined study characteristics, primary and secondary outcomes. Authors of studies with missing data will be contacted via phone and email. Selected studies will be assessed for risk of bias in the Distiller SR.

\section{c. Data collection process:}

De-duplication of the studies and extraction of data items into predefined forms will be done in the DistillerSR and exported into Microsoft Excel. Also, Prisma flow chart will be created in the DistillerSR. The following data items will be extracted from selected studies:
a. First author's surname and year of publication.
b. prevalence of hepatitis $\mathrm{C}$ virus infection in Nigeria.
c. sample size.
d. method of testing (ELISA, RDT, and PCR).
e. and sub-populations: blood donor, prisoner, pregnant women, etc of the tested subjects.

Data in Excel format will be imported to the CMA Software for meta-analysis.

\section{Data items (Measurable outcomes):}

Data items to be extracted include the following: prevalence of hepatitis $C$ virus infection in Nigeria reported as the number of cases in sample size or prevalence or incidence which is convertible to prevalence. Data for subgroup analysis will include prevalence in children, adults, persons living with HIV/AIDS, people in prisons, blood donors, sex workers, sickle cell patients, pregnant women, multiply transfused persons; and also, co-infection with HBV in Nigeria. Hence, the measurable outcome is the proportion of people with hepatitis $\mathrm{C}$ virus infection in Nigeria and among different sub-populations and its effect size is the prevalence. 


\section{Risk of bias}

The risk of bias in included studies will be accessed for the individual studies using the National Institute of Health (NIH) Quality assessment tool for observational cohort and cross-sectional studies (22). This will be cross-checked with the Cochrane tool of risk of bias assessment for the strength of the body of evidence; i.e. using specific relevant items from this tool to assess the strength of the body of evidence.

The following areas shall be assessed and any study with extreme bias will be excluded following a consensus decision.

1. Method of testing/reporting will be assessed at the outcome level.

2. Reporting of study: whether prevalence with confidence interval or number of positive cases per sample size is reported at the outcome level

3. Heterogeneity will be assessed at the study level

4. Publication bias will be assessed at the study level.

5. Sensitivity testing will be performed at the study level using the include/exclude function in the CMA Software.

\section{Data synthesis}

a. Studies that passed the methodological quality assessment using the NIH quality assessment tool will be extracted. The results will be presented in tabular format in addition to a narrative synthesis.

b. The following shall be included in the meta-analysis;

i. The reported prevalence of hepatitis $C$ virus infection and sample size by individual studies and subpopulations. Effect size is the prevalence. This variable must be present for a study to be included. It is the primary measurable outcome.

ii. A subpopulation of study subjects as categorical data and different test methods will be used as moderators.

c. Eligible studies will be quantitatively analyzed using the CMA Software Version 3 (BioStat, USA). For each reported prevalence of hepatitis $C$ virus infection, standard error, and variance for each specific eligible study will be calculated by the CMA software. Subgroup analysis will also be done.

\section{Assessment of Meta-bias}

To test for heterogeneity: Cochrane's $Q$ value and its $p$-value, $\mathrm{I}^{2}, \otimes^{2}$ will be used. The effect size is the prevalence at a $95 \%$ Confidence Interval (Cl, 95\%). Publication bias will be assessed using a funnel plot. As a rule of thumb, $I^{2}$ values of less than $40 \%$ will be considered low heterogeneity while values $>40$ but $<$ $75 \%$ will be considered moderate and values $>75 \%$ are high.

\section{Further Analysis}


Subpopulations in this study are categorical and will be used for subgroup analysis. Diagnostic testing methods will be used as moderators. The pooled effect size for national prevalence and subgroup analysis will be reported in forest plots. Both random and fixed effect models will be assessed, and the appropriate model will be taken based on the forest plots. Publication bias in the selection of studies will be tested using a funnel plot (trim and fill method) and test for funnel plot asymmetry. A cumulative meta-analysis will be performed to check for the trend in the prevalence of hepatitis c virus infection in Nigeria over the years.

\section{Presentation and Reporting of Results}

The study selection process will be summarised in a flow diagram according to the PRISMA 2015 (23) Statement and PRISMA-P Checklist (24). A table of the search strategy in various databases showing text words, MeSH, and entry terms will be included. A list of included studies will be summarized in a table. Quantitative data such as effect size (prevalence), $95 \% \mathrm{Cl}, \mathrm{P}$ values, and relative weights assigned to studies and heterogeneity tests will be included in the forest plots. A table of quality scores and risk of bias of each eligible study will be included. Forest plots to show sub-group analysis will be included. A cumulative meta-analysis to check for trends will also be included.

\section{Discussion}

The study will discuss the implications of the summary prevalence of hepatitis $\mathrm{C}$ virus infection in Nigeria. It will estimate the burden of the disease in Nigeria and the consequences to health resources and well being of residents in Nigeria. It will also weigh the implications of the hepatitis $\mathrm{C}$ infection in relation to liver cancer and diseases in Nigeria.

The final study will be published in a peer-review journal. The strength of evidence of any study done using this protocol wil be assessed by using NIH Quality Assessment of Systematic Reviews and MetaAnalysis.

\section{Abbreviations}

AJOL: African Journal Online

AGCPN: Association for Good Clinical Practice in Nigeria

CINAHL: Cumulative Index of Nursing and Allied Health Literature

HCV: Hepatitis C Virus

CMA: Comprehensive Meta-Analysis Software

$\mathrm{NIH}$ : National Institute of Health

PRISMA: Preferred Reporting Items for Systematic Review and Meta-analysis 
PROSPERO: International Prospective Register of Systematic Reviews

ELISA: Enzyme-linked Immunosorbent Assay

RDT: Rapid Diagnostic Test

PCR: Polymerase Chain Reaction

\section{Declarations}

\section{Ethics and Dissemination}

Ethical approval will not be required, since this study will rely solely on the secondary source of data i.e. data from published data. This review will provide important data on prevalence hepatitis $\mathrm{C}$ virus infection in Nigeria and the burden of the disease. Results from this study will prompt policy makers on the need and extent of intervention required in the prevention and treatment of the disease in Nigeria. The final report of this study will be published in a peer-reviewed journal and the findings will be made available to various policy makers and health experts that manage patient at risk or infected with hepatitis $C$ virus.

\section{Contributions}

$\mathrm{EN}, \mathrm{HO}$ and $\mathrm{SO}$ conceived the project, EN, HO, BA, SO and AN designed the study, BA and IR will do PubMed searches, screening and review; $\mathrm{HO}$ and DO will review AJOL search, UA, MC, and NO will review Embase, Web of Sciences and Scopus searches and review; SO, GO and AN will review Google scholar and Web of Science and DE and YG will search and review CINAHL database, CE and OA will search and review articles from Cochrane Database while $A D$ and UO will review Researchgate.

\section{Support}

Association for Good Clinical Practice in Nigeria (AGCPN) provided the platform and funding for this review

\section{Guarantor of the Review}

Dr. Emmanuel Nna

\section{Ethical approval and consent to participate}

Not applicable

\section{Consent for publication}

Not applicable 


\section{Competing interest}

The authors declare no competing interest

\section{Acknowledgments}

Not applicable

\section{Amendments}

Important protocol amendments post registration will be recorded and included in dissemination.

\section{References}

1. Kim CW, Chang K-M. Hepatitis C virus: virology and life cycle. Clin Mol Hepatol. 2013;19(1):17-25.

2. Ejiofor OS, Emechebe GO, Igwe WC, Ifeadike CO, Ubajaka CF. Hepatitis c virus infection in Nigerians. Nigerian Medical Journal. 2010;51(4):173.

3. Kesson AM. Diagnosis and management of paediatric hepatitis c virus infection. J Paediatr Child Health. 2002 Jun;38(3):213-8.

4. Eze JC, Ibeziako NS, Ikefuna AN, Nwokoye IC, Uleanya ND, Ilechukwu GC. Prevalence and risk factors for hepatitis $\mathrm{c}$ and human immunodeficiency virus coinfection among children in Enugu, Nigeria. Afr J Infect Dis. 2014;8(1):5-8.

5. Alkindi S, Nada A-U, Jaju S, Pathare A. Prevalence of Hepatitis B, Hepatitis C, and HIV in multiply transfused Sickle Cell disease patients from Oman. Mediterranean journal of hematology and infectious diseases. 2019;11(1).

6. Jemilohun AC, Oyelade BO, Oiwoh SO. Prevalence of hepatitis c virus antibody among undergraduates in Ogbomosho, southwestern Nigeria. Afr J Infect Dis. 2014;8(2):40-3.

7. D L. Hepatitis C: Public health strategies. J Hepatol. 1999;31 Suppl 1:146-51. https://europepmc.org/article/med/10622578

8. Wasley A, Alter MJ. Epidemiology of hepatitis C: geographic differences and temporal trends. Semin Liver Dis. 2000;20(1):0001-16. http://www.thieme-connect.de/DOI/DOI?10.1055/s-2000-9506

9. Adewuyi JO. Prevalence of antibodies to hepatitis c virus among normal blood donors and multitransfused sickle-cell anaemia patients in Nigeria. Trop Doct. 1996;26(1):29-30. http://journals.sagepub.com/doi/10.1177/004947559602600111

10. Ejiofor OS, Ibe BC, Emodi IJ, Ikefuna AN, Ilechukwu GC, Emechebe G, et al. The role of blood transfusion on the prevalence of hepatitis $\mathrm{c}$ virus antibodies in children with sickle cell anaemia in Enugu, southeast Nigeria. Niger J Clin Pract. 2009;12(4):355-8.

11. Umumararungu E, Ntaganda F, Kagira J, Maina N. Prevalence of hepatitis c virus infection and its risk factors among patients attending Rwanda military hospital, Rwanda. BioMed Research International. 2017;2017:1-7. https://www.hindawi.com/journals/bmri/2017/5841272/ 
12. Olubuyide IO, Ola SO, Aliyu B, Dosumu OO, Arotiba JT, Olaleye OA, et al. Hepatitis B and C in doctors and dentists in Nigeria. QJM. 1997;90(6):417-22.

13. Ejiofor SO, Ibe B, Emodi I, Ikefuna A, llechukwu G, Emechebe G, et al. Sociodemographic differences in the distribution of hepatitis $\mathrm{c}$ virus antibodies among children with sickle cell anaemia in Enugu, southeast Nigeria. Orient Journal of Medicine. 2009;21(1-4).

https://www.ajol.info/index.php/ojm/article/view/54469

14. Lavanchy D, Gavinio P. Hepatitis C. Can J Gastroenterol. 2000 Aug;14 Suppl B:67B-76B.

15. Health $\mathrm{NI}$ of. NIH consensus statement on management of hepatitis C. NIH Consens State Sci Statements. 2002; 19:1-46.

16. Frank C, Mohamed MK, Strickland GT, Lavanchy D, Arthur RR, Magder LS, et al. The role of parenteral antischistosomal therapy in the spread of hepatitis $C$ virus in Egypt. The Lancet. 2000;355(9207):887-91.

17. World Health Organization (WHO). Hepatitis C. Fact Sheet No. 164. Revised October 2000. 2000.

18. Hoofnagle JH. Hepatitis C: the clinical spectrum of disease. Hepatology. 1997;26(S3):15S-20S.

19. Armstrong GL, Wasley A, Simard EP, McQuillan GM, Kuhnert WL, Alter MJ. The prevalence of hepatitis $C$ virus infection in the United States, 1999 through 2002. Annals of internal medicine. 2006;144(10):705-714.

20. Alter MJ. Epidemiology of hepatitis C virus infection. WJG. 2007;13(17):2436.

21. Han R, Zhou J, François $C$, Toumi M. Prevalence of hepatitis $C$ infection among the general population and high-risk groups in the EU/EEA: a systematic review update. BMC infectious diseases. 2019;19(1):655.

22. Lung NH, Institute B. Quality Assessment Tool for Observational Cohort and Cross-Sectional StudiesNHLBI, NIH. National Institutes of Health. 2014. 2015.

23. Preferred reporting items for systematic review and meta-analysis protocols (PRISMA-P) 2015 statement | SpringerLink [Internet]. [cited 2020 Oct 28]. Available from: https://link.springer.com/article/10.1186/2046-4053-4-1

24. Moher D, Stewart L, Shekelle P. Implementing PRISMA-P: recommendations for prospective authors. Syst Rev. 2016; 28;5(1):15.

\section{Supplementary Files}

This is a list of supplementary files associated with this preprint. Click to download.

- PRISMAPchecklistforhepcstudy.docx 